For whom the bell tolls

\title{
For whom the bell tolls
}

\section{Geoffrey Hughes}

n 1997, when it took office, the Labour Government promised that the National Health Service (NHS) was safe in its hands. The founding principles defined in 1946, of universality, comprehensiveness and predominantly free healthcare, seemed safe. When, in 2000, The NHS Plan added "patient choice" to the list (patients choose services and not services choose patients), it seemed a decent proposition despite being unclear how compatible it would be with the other three principles.

The introduction of performance targets and payment by results in recent years aimed to improve standards and to develop competition both within the NHS and with independent providers. Achievement of performance targets (regardless of the often nefarious means used to achieve them) certainly gave the government some sound bite headlines with which to sell to the public their belief that the huge financial investment in the NHS was having a positive impact. In the run up to the 2005 general election most people believed that all was reasonably well in the health world, and only those with an ingrained scepticism as well as perennial doubters had cause to think otherwise.

Since the general election, the voice of optimism many people had is increasingly hard to hear, drowned out by a rising volume of concern from previous supporters as well as from the sceptics and doubters. The NHS is transforming into a mishmash of organisations that must increasingly fend for themselves, answerable to the market and its forces, and not to ministers and civil servants as it once was.

What we are witnessing, instead of improvements and expansion, are cutbacks. The current focus on budget deficits reported by primary care and NHS trusts that are in the red deliberately ignores the fact that others are in financial balance purely because of significant cuts they have already made in the services they provide, cuts made to balance the books. The desire to meet targets in some sectors of the NHS brings other sectors to their knees. It can be argued that overall, patients experience harm rather than benefit from the government's fetish with performance targets.

Rationing of services has always been intrinsic to healthcare anywhere, and the NHS has never been any different, although the word itself is rarely uttered, being disguised in other sobriquets. It is not just the NHS that rations. As local councils were given responsibility for what is known as social care, following devolvement from the NHS, stricter and stricter eligibility criteria are now used by many councils, criteria aimed to curb spending; in simple terms fewer people receive social care.

The whys and wherefores of the financial pickle and disarray that the NHS is in will be given different emphases by different prosecutors of the case; a consensus will probably be achieved if the gross and negligent miscalculation of the impact of the new consultant and general practitioner contracts is included. The dissembling about this and the blame being apportioned on greedy and lazy doctors is malignant and shameful. To penalise the end user (the public) for the government's financial incompetence is equally shameful. The manner in which clinical staff of all layers is managed is demeaning. The methods and psychology used by human resource experts and good managers to nurture and support staff is missing. Divide and rule is common.

The NHS (at both national and local levels) has always tended to rule by centralised decision making, but the tone and manner is not what it once was; it is currently strident, stentorian and sometimes hysterical. Transparency of process is notable by its absence. True consultation is almost non-existent. Management is dismal, oblique, obtuse and unimaginative (apart from finding increasingly diverse ways to absolve itself of accountability-where does the buck stop?). The chasm between clinicians and management is widening at a rate unimaginable even 2 years ago.

The mantra of choice and the promise (in The NHS Plan) that the NHS will be "responsive to the needs of different groups and individuals ..., that patients and citizens will have a greater say in the NHS and the provision of services will be based on patients' needs" sounds as real as a fairy tale written by Hans Christian Andersen. Trusts (primary care and NHS) are making decisions with little coherence; cutbacks and the redefining of services are haphazard, inconsistent and with little view to the long term, apart from the aim to sell off the NHS' crown jewels. The repetitive statements that care will be provided "locally and closer to home" no longer washes with the electorate or the committed health professionals expected to deliver it. It is inconsistent with the reality of what is happening.

The specialty, faculty (as it once was) and the College can take great pride in the response to reforms of recent years, in particular the 4 hour target. It was a supreme team effort to work positively and professionally to government demands. A lot of credit is due to a lot of people. The current model for the reconfiguration of "accident and emergency" services and the means used to deliver the message typifies the perverse and perhaps crass way the government operates and it will be difficult for the specialty to respond so positively this time.

The Secretary of State fiddles while the NHS burns. Its services are being thrown onto a bonfire, the ashes of which will blow away on the political air currents of the time. In the tale of Nero and the city of Rome in $\mathrm{AD}$ 64, the fires may have been deliberately started, the arsonist being Nero himself.

Emerg Med J 2007;24:150.

doi: 10.1136/emj.2007.046144

Correspondence to: Prof $G$ Hughes, The Emergency Department, Royal Adelaide Hospital, North Terrace. Adelaide 5000, Australia; cchdhb@yahoo.com

Competing interests: None declared. 